\title{
PAEDIATRIC CLINICAL TEACHING: ADDRESSING PARENTAL CONCERNS
}

\author{
Suresh S. Vadakedom¹, Geetadevi Madavikutty², Sajithkumar Radhakrishnan ${ }^{3}$ \\ ${ }^{1}$ Associate Professor, Department of Paediatrics and Medical Education, Government Medical College, Kottayam. \\ ${ }^{2}$ Associate Professor, Department of Community Medicine and Medical Education, Government Medical College, Kottayam. \\ ${ }^{3}$ Professor, Department of Infectious Diseases and Medical Education, Government Medical College, Kottayam.
}

ABSTRACT
BACKGROUND
Bedside clinical case discussion is an integral part of medical education. Cooperation of both the child and parent is essential in
the successful conduct of paediatric clinical discussion. Apprehension on being examined by a trainee, fear of worsening of illness,
awareness regarding patient rights, risk of hospital acquired infections, etc. are often identified as reasons for non-cooperation on
the part of the patients.

\section{OBJECTIVES}

To identify the concerns of parents when their children admitted in paediatric wards are subjects in clinical teaching.

\section{METHODS}

A twenty-five item peer validated questionnaire was devised focusing on parental attitudes, concerns and suggestions on student behaviour in Paediatric wards. Ninety six mothers of children admitted to paediatric wards of Govt. Medical College, Kottayam, participated in the study; quantifying their concern on a 3-point Likert scale. Data analysed by descriptive statistics.

\section{RESULTS}

Out of 83 who completed the questionnaire, 82 (98.8\%) expressed mild-moderate degree of concern regarding their children as subjects in clinical teaching. Major concerns expressed include reduction in rest time (44\%), perceived increase in risk of hospital acquired infections (40\%), fear of increase in child's pain (39\%) or aggravation of the illness (38\%). Majority (94\%) suggested that medical students require training to build rapport and improve clinical examination skills before examining paediatric patients. Supervision by the faculty during student examination is suggested.

\section{CONCLUSIONS}

Mild-to-Moderate degree of concern expressed by parents regarding children as subjects in bedside teaching. Students probably need more training for examination and building rapport.

\section{KEYWORDS}

Bedside Clinics, Parental Concerns, Paediatric Clinical Teaching.

HOW TO CITE THIS ARTICLE: Vadakedom SS, Madavikutty G, Radhakrishnan S. Paediatric clinical teaching: addressing parental concerns. J. Evolution Med. Dent. Sci. 2016;5(54):3633-3635, DOI: 10.14260/jemds/2016/837

\section{INTRODUCTION}

Clinical teaching is concerned with the acquisition of the multitude of skills and competencies to enable effective practice in the health care professions. The learning may take place in a range of settings. Bedside teaching has always been the cornerstone of clinical teaching for the health professions. By bedside teaching we mean patient-based and patientorientated teaching and learning; taking place in natural health related environments. Effective bedside teaching can sometimes be a difficult juggling act to perform. The clinical teacher needs to be aware of not just the learner, but also of the welfare of the patient. ${ }^{1}$

Patients, students, residents and teachers all seem to favour bedside teaching for varying reasons. Despite this, the practice of bedside teaching is declining. Reasons to explain

Financial or Other, Competing Interest: None.

Submission 02-06-2016, Peer Review 24-06-2016,

Acceptance 02-07-2016, Published 07-07-2016.

Corresponding Author:

Dr. Suresh S. Vadakedom,

Vadakkedam (Parayil),

Athirampuzha P.O.

Kottayam-686562, Kerala.

E-mail:svadakku@yahoo.co.in

DOI: $10.14260 /$ jemds $/ 2016 / 837$ this decline include the increased patient turnover in hospitals, the assumed violation of patients' privacy and an increased reliance on technology in the diagnostic process. ${ }^{2}$ Hence, methods should be sought to improve the patient cooperation and conducting bedside clinics to obtain desired outcomes respecting patient rights.

Different methods have been devised to improve the clinical training like One-Minute Preceptor (OMP), role plays, simulated patients, skills labs and so on. 3,4 "He who studies medicine without books sails an uncharted sea, but he who studies medicine without patients does not go to sea at all," as stated by the great clinical teacher and Father of Modern Medicine Sir William Osler.

A study was conducted among the parents of paediatric patients to know the parental concerns when the children are subjects for bedside clinics. Identifying the factors for poor patient cooperation may help to improve the student awareness on the causes of dissatisfaction among patients and counsel the parents by the teachers to ensure their participation and cooperation.

\section{METHODOLOGY}

A descriptive study using a pre-validated structured questionnaire was conducted among 96 mothers after getting 
IRB approval and informed consent in the Paediatric wards of Government Medical College, Kottayam in Kerala. The questionnaire consisted of 25 items to be answered on a threepoint Likert scale (Score $0-2$ ) and studied 3 aspects namely parental attitudes to bedside teaching in 5 statements, parental concerns addressed in 15 statements and parental suggestions in 5 statements devised after peer review and content validation. Data analysed using descriptive statistics.

\section{RESULTS}

Out of 96 mothers approached with the questionnaire, 85 participated. Responses were complete in 83 (86.5\%).

Regarding the parental attitude, all the participants $(n=83)$ admitted that it was right on the part of medical students to collect data and examine children admitted in paediatric ward for their study purpose and thought that it was essential for medical students to examine and learn from patients $(82 / 83$; 98.7\%); $91.5 \%$ felt that examination by medical students may help in arriving at a diagnosis and treatment of their child.

\begin{tabular}{|c|c|c|}
\hline Score & Number (n=83) & Percentage \\
\hline $\begin{array}{c}\text { Mild concern } \\
(0-10)\end{array}$ & 53 & $63.9 \%$ \\
\hline $\begin{array}{c}\text { Moderate concern } \\
(11-20)\end{array}$ & 29 & $34.9 \%$ \\
\hline $\begin{array}{c}\text { Severe concern } \\
(21-30)\end{array}$ & 1 & $1.2 \%$ \\
\hline Total & $\mathbf{8 3}$ & $\mathbf{1 0 0 \%}$ \\
\hline \multicolumn{2}{|r}{ Table 1: Parental Concern Score } \\
\hline
\end{tabular}

Parental concerns were studied based on 15 statements on a three-point Likert scale with minimum score of 0 and maximum score of 2 . Average score among the study group was $8.73 \pm 2.31$ with majority (98.8\%) expressing mildmoderate degree of concern (Table 1), while their child is a subject for bedside clinical teaching. Analysing the reasons for parental concerns, $53 \%$ opined that it reduces rest time invading their privacy and feared an increase in the risk of hospital acquired infections (48.1\%); 38 (46.9\%) participants thought that examination by the students aggravated child's pain and illness; 29 (34.9\%) out of 83 participants opined that students are examining without proper training and their child dislikes being examined by the students (12\%). Few other concerns noted in the study were difficulty in timely feeding of the child and chance of missing ward rounds by the consultants (Table 2).

\begin{tabular}{|c|c|c|}
\hline $\begin{array}{l}\text { Major Parental } \\
\text { Concerns }\end{array}$ & $\begin{array}{c}\text { Number } \\
(n=83)\end{array}$ & Percentage \\
\hline $\begin{array}{l}\text { Reduction in Child's Rest } \\
\text { Time and Reduce Privacy }\end{array}$ & 44 & $53.0 \%$ \\
\hline $\begin{array}{l}\text { Fear of Increased Risk of } \\
\text { Infections }\end{array}$ & 40 & $48.1 \%$ \\
\hline $\begin{array}{l}\text { Fear of Aggravation of } \\
\text { Child's Illness and Pain }\end{array}$ & 38 & $46.9 \%$ \\
\hline $\begin{array}{l}\text { Students Examining without } \\
\text { Proper Training }\end{array}$ & 29 & $34.9 \%$ \\
\hline $\begin{array}{l}\text { Difficulty in Completing Lab } \\
\text { Tests or Consultations }\end{array}$ & 19 & $22.9 \%$ \\
\hline $\begin{array}{c}\text { Child Dislikes being } \\
\text { Examined by Students }\end{array}$ & 10 & $12.0 \%$ \\
\hline \multicolumn{3}{|c|}{ Table 2: Major Parental Concerns Identified } \\
\hline
\end{tabular}

Majority (94\%) suggested that medical students require training to build rapport and improve clinical examination skills before examining paediatric patients. Supervision by the faculty during student examination was also suggested (90\%).

\section{DISCUSSION}

Bedside clinics are integral part of medical teaching in all clinical subjects. It introduces the medical student to the realities in clinical medicine with real time patients. Conducting bedside clinics is an art learnt by practice and built on the knowledge of the teacher. The process of bedside clinics starts with the introduction of the topic by the teacher followed by one-to-one interaction of the medical student with designated patient. The student interacts with the patient to identify the patient problem and move on to the clinical examination to arrive at the clinical diagnosis. This is followed by the clinical presentation in a group of peers and the teacher, in presence of the patient. The aim of conducting bedside clinics is to improve the different skills like building rapport, effective communication, understanding patient problems, interpreting clinical data, symptom analysis, clinical examination skill and summarizing the data to arrive at a rational protocol for the management. Examples of skills best taught at the bedside also include communication skills, clinical skills and professionalism. Several barriers and challenges to bedside teaching have been reported and many clinical teachers are uncertain about effective strategies for resolving them. ${ }^{5}$ Changes in curricula for health care professionals place an increasing importance of systematic learning of core skills and demonstration of skills acquisition and competency. Changes in the politics of health care with increased accountability and patient autonomy have also affected all clinical learning environments. ${ }^{1}$

\section{Successful Conduct of Bedside Clinical Teaching Depends on Different Factors}
A. Patient related.
B. Student related.
C. Teacher related.

Students' enthusiasm and teachers' knowledge and skills are major factors that decide the success of the clinical teaching. Student motivation can be improved by involving them as primary reporters of patient progress to a limited extent without affecting the quality of care. This improves the self-confidence of the novice and earns a respectful position for him between the teacher and the patient.

Ensuring the patient cooperation is critical in the conduct of paediatric clinics. Children when sick are irritable and uncooperative for clinical examination. Even consultants and experienced doctors may find it difficult for examination when the child is irritable and uncooperative. Ensuring parental cooperation, which is important for paediatric clinical teaching depends on the skills of the teacher as well as the medical student. Proper communication from the student and the teacher is essential to relieve the parental anxiety when the sick child is a subject for bedside clinical teaching. Often clinics go incomplete due to the poor cooperation from the patients and parents and clinical examination skills' training goes unsupervised. This leads to poor clinical examination skills and lack of confidence among medical students in eliciting and interpreting the signs in patients. 
The present study is addressing the perceptions and concerns of parents of children admitted in the paediatric wards regarding the behaviour of the medical students and identify the reasons for their poor cooperation in clinical teaching. As observed mild-moderate degree of concern was expressed by $98 \%$ of the parents when their child is a subject for clinical teaching. Improving patient cooperation is essential for the fruitful conduct of bedside clinic, which is the backbone of learning any clinical subject in medical field. Medical students should become aware and sensitive to the parental concerns regarding their sick child and willing to respond to their concern in an empathetic manner. They should be ready to acknowledge patient rights and minimize their discomfort during the learning process. ${ }^{6}$ The duty of medical teachers never ends with the clinical discussion and skills training, but ensuring patient comfort, professionalism and communication skill also should be taught and demonstrated during the training sessions. The teacher should be able to demonstrate these skills to the students and ensure that students practice them in all their patient encounters with sincerity and humanity. The concept of patient rights and what it means 'to be a patient' should be discussed at the beginning of the student's clinical encounters to ensure patient safety.

Proper briefing regarding the topics and learning objectives to the students prior to the contact with the patient can guide the student to identify the learning objectives and obtain the needed clinical skills without causing discomfort to the patient.7,8 This study also emphasizes the need of introducing communication skill training to the medical students.

A simulated setting is optimal for beginning the attainment of selected clinical skills abilities. Simulated settings include skills lab, mannequins, simulated patients who can imitate clinical setting and even mock drills. The level of fidelity and the physical setting needed for a simulated learning opportunity depends upon the intended learning objective. An advantage of simulated learning opportunities is that students can practice skills repetitively with no inconvenience to patients or risk to their safety. However, simulated experiences do not preclude experiences with actual patients. ${ }^{9}$ Students should have adequate demonstrations including videos or using skills lab on clinical examination skills before they get accustomed with the patients, so as to reduce the patient concerns and discomfort.

Patient and caregivers may be given a chance to express their concerns and feedback on the student behaviours, which can help a lot in improving the bedside manners of young doctors. The guidance and role modelling of teachers also will help to improve the soft skills and clinical teaching outcomes of the new generation of doctors.

\section{CONTRIBUTIONS}

SKR conceived the study and critically reviewed the manuscript; SSV conducted the study, data collection, analysis and preparation of the manuscript and will be the guarantor; GDM reviewed the manuscript and statistical support.

\section{ACKNOWLEDGEMENTS}

Authors are thankful to Dr. P. Savida, Superintendent, ICH and Dr. Remla Beevi, Principal, Govt. Medical College, Kottayam, for the permission and support for conducting the study. We are grateful to Prof. Tejinder Singh and the faculty at MCI Nodal Centre, CMC, Ludhiana, for the guidance and help. We also thank all the participants of this study.

\section{REFERENCES}

1. Gill D. Teaching and learning at the bedside. (www.faculty.londondeanery.ac.uk/learning/teaching_a nd_learning).

2. Peters $\mathrm{M}$, Cate TO. Bedside teaching in medical education: a literature review. Perspect Med Educ 2014;3(2):76-88.

3. Neher JO, Stevens NG. The one-minute preceptor: shaping the teaching conversation. Fam Med 2003;35(6):391-3.

4. Akaike M, Fukutomi M, Nagamune M, et al. Simulationbased medical education in clinical skills laboratory. J Med Invest 2012;59(1-2):28-35.

5. Ramani S. Tips for effective bedside clinical teaching. MedEdPORTAL Publications 2006;2:220. (https://www.mededportal.org/publication/220).

6. Janicik RW, Fletcher KE. Teaching at the bedside: a new model. Med Teach 2003;25(2):127-30.

7. Cox K. Planning bedside teaching. The Medical Journal of Australia 1993;158:280-2.

8. Salam A, Siraj HH, Mohamad N, et al. Bedside teaching in undergraduate medical education: issues, strategies, and new models for better preparation of new generation doctors. Iran J Med Sci 2011;36(1):1-6.

9. Issenberg S, McGaghie WC, Petrusa ER, et al. Features and uses of high fidelity simulation that lead to effective learning: a BEME systematic review. Med Teacher 2005;27(1):10-28. 